\title{
OS DANOS SOCIOAMBIENTAIS NA SOCIEDADE MODERNA CONSUMOCENTRISTA: A CONTINUAÇÃO DO ANTROPOCENTRISMO EM DESFAVOR A UMA CULTURA SOCIOECOLÓGICA EXPRESSA PELOS DIREITOS DA NATUREZA
}

\author{
Agostinho Oli Koppe Pereira ${ }^{1}$ \\ Cleide Calgaro ${ }^{2}$
}

\begin{abstract}
Resumo. No presente artigo tem-se como objetivo, através do método analítico dedutivo, analisar a sociedade moderna consumocentrista e a manutenção do antropocentrismo, em desfavor dos aspectos socioambientais, procurando demonstrar os efeitos maléficos, dessa opção, para o meio ambiente e ao ser humano. A lei é um elemento facilitador da implementação dos conceitos de possibilidade, ou não da sustentabilidade social e ambiental, motivo pelo qual se trabalha os direitos da natureza. Assim, por final, trabalha-se com os direitos da natureza, mostrando possíveis soluções para minimizar os efeitos deletérios do consumocentrismo e antropocentrismo no contexto da sociedade contemporânea moderna.
\end{abstract}

Palavras-chave. Consumocentrismo; socioambientalismo; direitos da natureza; sociedade moderna; sustentabilidade.

\section{SOCIO-ENVIRONMENTAL DAMAGE IN MODERN CONSUMEROCENTRIST SOCIETY: THE CONTINUATION OF ANTHROPOCENTRISM AGAINST A SOCIOECOLOGICAL CULTURE EXPRESSED BY THE RIGHTS OF NATURE}

Abstract. This article aims, through the deductive analytical method, to analyze the modern consumerocentrist society and the maintenance of anthropocentrism, in detriment of the socioenvironmental aspects, seeking to demonstrate the harmful effects of this option for the environment and the human being. Law is a facilitating element in the implementation of the concepts of possibility, or not of social and environmental sustainability, which is why we work on the rights of nature. Finally, we work with the rights of nature, showing possible

\footnotetext{
${ }^{1}$ Doutor em Direito pela Universidade do Vale do Rio dos Sinos - UNISINOS. Pós-Doutor em Direito pela Universidade do Vale do Rio dos Sinos - UNISINOS. Mestre em Direito pela Universidade Federal de Pernambuco UFPE. Professor colaborador do Mestrado em Direito da Universidade de Passo Fundo. ORCID: https://orcid.org/0000-0003-2939-7534. CV: http://lattes.cnpq.br/5863337218571012.

E-mail: agostinho.koppe@gmail.com

2 Doutora em Ciências Sociais na Universidade do Vale do Rio dos Sinos - UNISINOS. Pós-Doutora em Filosofia e em Direito ambos pela Pontifícia Universidade Católica do Rio Grande do Sul - PUCRS. Doutoranda em Filosofia pela Pontifícia Universidade Católica do Rio Grande do Sul - PUCRS, na condição de taxista CAPES. Doutoranda em Direito pela Universidade de Santa Cruz do Sul - UNISC. Professora da Graduação e Pós-Graduação em Direito na Universidade de Caxias do Sul. É Líder do Grupo de Pesquisa "Metamorfose Jurídica" da Universidade de Caxias do Sul-UCS e Vice-Líder do Grupo de Pesquisa "Filosofia do Direito e Pensamento Político" da Universidade Federal da Paraíba-UFPB. Atua como pesquisadora no Grupo de pesquisa "Regulação ambiental da atividade econômica sustentável (REGA)" da Escola Superior Dom Helder Câmara. Orcid: https://orcid.org/0000-0002-1840-9598. CV: http://lattes.cnpq.br/8547639191475261.

E-mail: ccalgaro1@hotmail.com
}

Revista de Direito e Sustentabilidade | e-ISSN: 2525-9687 | Belém | v. 5 | n. 2 | p. 01 - 19 | Jul/Dez. 2019. 
solutions to minimize the deleterious effects of consumerocentrism and anthropocentrism in the context of modern contemporary society.

Key words. Consumerocentrism; socioenvironmentalism; rights of nature; modern society; sustainability.

\section{INTRODUÇÃO}

Neste artigo, que traz como título: "os danos socioambientais na sociedade moderna consumocentrista: a continuação do antropocentrismo em desfavor a uma cultura socioecológica expressa pelos direitos da natureza", os Autores partem do seguinte problema: a sociedade moderna consumocentrista induz a utilização exacerbada dos recursos naturais, para a produtividade, em detrimento da qualidade de vida do ser humano e preservação da natureza?

A partir desse problema, os Autores traçam como objetivo principal determinar quais os critérios possíveis para se vislumbrar, na modernidade contemporânea, uma sociedade consumocentrista.

Além desse aspecto central, dois problemas secundários perfazem o artigo: um, como a manutenção da teoria antropocentrista, pode influenciar em desfavor dos aspectos socioambientais, percebendo, o socioambiental, como imbricamento e/ou simbiose que se entende existir entre o ser humano e a natureza? Dois, a cultura socioecológica, expressa pelos direitos da natureza, possui, em suas bases, manancial jurídico capaz de se antepor aos avanços de uma sociedade consumocentrista, que embala a exploração ambiental além dos limites da sustentabilidade?

Para atender a esses questionamentos traçou-se com objetivos secundários do artigo: para o primeiro problema secundário, analisar os problemas socioambientais criados pela sociedade consumocentrista, em seu aspecto antropocêntrico e suas consequências tanto ao meio ambiente quanto ao ser humano, vislumbrando o Direito, principalmente no que se refere ao disposto no artigo 225 da Constituição brasileira de 1988; para o segundo, buscar na cultura socioecológica, expressa pelos direitos da natureza, dentro de seus aportes em que a natureza pode se apresentar como sujeito de direito, a possibilidade de interferir, através de seus aspectos jurídicos, reduzindo os efeitos socioambientais nefastos causados por esse modelo consubstanciado na modernidade consumocentrista. 
Para a obtenção dos resultados buscados, os Autores fazem uso, para este artigo, do método analítico. Através deste, pretende-se efetuar análise sobre o consumocentrismo, a cultura socioecológica, expressa pelos direitos da natureza, e a legislação constitucional pertinente ao meio ambiente ecologicamente equilibrado, para a busca de soluções aos problemas elencados e alcance dos objetivos propostos.

Para desenvolver o trabalho, na busca do alcance dos objetivos propostos, dividiu-se o artigo em três subtítulos: o primeiro, a sociedade moderna consumocentrista, no qual se expõe o surgimento e as características dessa sociedade, e o incandescimento do antropocentrismo como elemento motivador da exploração desmedida dos recursos ambientais, em detrimento da sustentabilidade socioambiental; no segundo subtítulo desenvolvido - O direito ao meio ambiente ecologicamente equilibrado: os danos socioambientais produzidos pela sociedade consumocentrista em desfavor da sustentabilidade - procura-se demonstrar a interferência do ser humano sobre a natureza e os danos a ela causados que, indiscutivelmente, possuem reflexos na própria sociedade humanada; o terceiro subtítulo - a cultura socioecológica expressa pelos direitos da natureza em face à sociedade moderna consumocentrista - é dedicado ao estudo na busca de soluções para resolver os problemas socioambientais causados pelo uso indiscriminado dos bens ambientais, vez que a teoria da natureza como sujeito de direitos possui o condão de propiciar um controle maior de proteção ao meio ambiente.

Feito o desenvolvimento do artigo dentro dos aspectos propostos, surge como conclusão preliminar - que será referendada em considerações mais adequadas no item próprio da conclusão - que a sociedade consumocentrista, desenvolvida sobre o hiperconsumo, propicia a utilização desmedida dos bens ambientais com consequências socioambientais que não atendem a propalada sustentabilidade, que é o elemento possibilitador da boa qualidade de vida humana dentro de um meio ambiente equilibrado.

Por final, espera-se que o presente artigo possa servir de alerta para os problemas socioambientais trazidos pelo uso indiscriminado dos bens da natureza e que seja possível dar ouvidos à cultura socioecológica, expressa pelos direitos da natureza, propiciando um diálogo aberto e democrático, pois é possível que ela possa trazer soluções adequadas para a minimização dos problemas socioambientais criados pela sociedade moderna consumocentrista. 


\section{A SOCIEDADE MODERNA CONSUMOCENTRISTA}

A sociedade contemporânea é o resultado do que se denominou chamar de modernidade, sociedade que implementou o rompimento com a Idade Média, também denominada de pré-moderna.

A sociedade moderna caracterizou-se por aspectos que se diferenciaram substancialmente de sua antecessora. Essa sociedade foi analisada por muitos autores que estabeleceram seus pareceres sobre ela, sendo impossível trazer à discussão, em um artigo, todos os aspectos salientados, motivo pelo qual se escolheu alguns autores para demonstrar as características mais marcantes, no entender dos Autores deste artigo, que poderia representar este período da história humana.

A modernidade, segundo Lyon, (2005, p. 35):

Se aplica à ordem social que emergiu depois do Iluminismo. Embora suas raízes se estendam até épocas bem anteriores ao Iluminismo, o mundo do moderno está marcado por seu dinamismo sem precedentes, por sua rejeição da tradição, ou sua marginalização, e por suas consequências globais.

De outra forma, para Giddens, (1991, p. 11) "a modernidade refere-se a estilo, costume de vida ou organização social que emergiram na Europa a partir do século XVII e que ulteriormente se tornaram mais ou menos mundiais em sua influência”. Em outra obra modernidade e identidade - Giddens (2002, p. 21), estabelece um sentido mais geral para a modernidade, alastrando o conceito disposto no livro "As consequências da modernidade", trabalhando com dimensões da modernidade, como industrialismo, capitalismo, vigilância e guerra total. Sobre o industrialismo dispõe o Autor:

\footnotetext{
A modernidade pode ser entendida como aproximadamente equivalente ao mundo industrializado desde que se reconheça que o industrialismo não é sua única dimensão institucional. Ele se refere às relações sociais implicadas no uso generalizado da força material e do maquinário nos processos de produção. Como tal é um dos eixos institucionais da modernidade. (GIDDENS 2002, p. 21)
}

Brüseke traz a técnica como uma das características fundamentais da modernidade, vez que a ciência e a tecnologia são elementos marcantes no desenvolvimento da sociedade moderna. Afirma o Autor: "o fato de que a modernidade, como época histórica, nasce com a ciência e a técnica moderna mostra hoje toda a sua virulência. Podemos até dizer que essa 
modernidade é tão penetrada pela técnica, que ela pode ser denominada e caracterizada como modernidade técnica.” (BRÜSEKE, 2010, p. 33)

São com esses aspectos da modernidade - ordem social que emergiu depois do Iluminismo; estilo, costume de vida ou organização social; tecnologia e ciência -, que se pretende trabalhar durante o desenvolvimento do presente artigo. Assim, nessa seara, pode-se afirmar que a modernidade perdura por mais de cinco séculos, embora já se esteja falando em pós-modernidade. Para o presente artigo, os Autores decidiram enfrentar o tema proposto, apenas, sob a ótica da modernidade, vez que entendem que esta não acabou, ainda que se possa dizer que se está aos portais da pós-modernidade, notando-se, neste aspecto, alguns avanços tecnológicos e comportamentos sociais que se diferenciam da modernidade.

Definidos os parâmetros do trabalho pode-se continuar verificando que a modernidade é um momento histórico altamente complexo, onde se estruturaram aspectos sociais - econômicos, jurídicos e espirituais - e científicos/tecnológicos, que demonstraram um significativo rompimento com as sociedades anteriores.

Assim, pode-se verificar que: no aspecto econômico deslocou-se a transferência de poder, pelo grau de parentesco, - realeza - para a substanciação do econômico, não mais se transferindo, o poder, através de títulos reais, para ser transferido através dos aspectos financeiros, fortalecido, principalmente, com o desenvolvimento do capitalismo; no que se refere ao jurídico, este acompanhou as modificações econômicas, fortalecendo a propriedade privada e corporativa além, é claro, conforme preconizou a Revolução Francesa, do estabelecimento da "igualdade" jurídica entre as partes; nos aspectos espirituais a modernidade procurou dar atribuições diversas para o Estado e para e Igreja - através da laicização do Estado - o que, de certa forma, atingiu também o Direito, que passou a ser totalmente exercido pelo Estado; porém, o que mais desvinculou a sociedade moderna, da prémoderna, foram os aspectos científicos e tecnológicos, vez que o chamado progresso da modernidade se deveu, fortemente, à revolução industrial. Como afirma Brüseke, (2010, p. 33) "Ciência, técnica, empresa capitalista - essa tríade faz a Revolução Industrial eclodir e não deixa dúvidas que estes tempo modernos distinguem-se sobremaneira dos tempos anteriores." 
Estas primeiras anotações foram necessárias para demonstração do campo em que se fez florescer o consumocentrismo dentro da sociedade moderna. Seguindo-se, pretende-se trabalhar sobre o que se entende por consumocentrismo.

$\mathrm{O}$ entendimento do que aqui se deseja colocar como consumocentrismo diverge das errôneas ideias que cercam essa palavra - de que, no consumocentrismo, o consumidor teria capacidade para impor sua vontade no meio mercadológico -. Esta é uma visão completamente distorcida, tanto da palavra, quanto do meio consumerista e é usada na área das finanças para orientar os fornecedores para o conhecimento do que pensa o consumidor. ${ }^{3}$

A palavra consumocentrismo - seguindo os parâmetros do antropocentrismo e do teocentrismo que colocam, o primeiro, o homem no centro do universo e o segundo, Deus no centro do universo - leva ao entendimento de que o consumo é o centro do universo e não o consumidor. Este é o sentido da palavra consumocentrismo que se trabalha no presente artigo. Assim:

Na sociedade moderna contemporânea, vive-se numa era consumista, em que os sujeitos estão mais ligados a mercadorias e a objetos do que, propriamente, a outros sujeitos, pois os valores funcionais dos objetos fazem com que o sujeito se sinta pertencente à sociedade de consumo - sujeito/objeto - e não à sociedade humana, no sentido de ligação sujeito/sujeito. O consumocentrismo é a dinâmica desse sistema e impõe ao sujeito a disciplina da alimentação, da cultura, da vestimenta, entre outras. Assim, o mesmo caracteriza-se pelo ciclo das mercadorias, que é efêmero, quando o sujeito precisa consumir para se sentir pertencente à sociedade contemporânea. (CALGARO; PEREIRA, 2018, p. 15)

Mantendo-se essas ideias, volta-se à modernidade, verificando que esta se desenvolveu, basicamente, sobre a produção e o consumo, senão vejamos: da denominada revolução industrial e do capitalismo - aquela, enquanto novo parâmetro de produção e este, enquanto sistema econômico - foi perfectibilizada a sociedade que perdura até a contemporaneidade.

Nesse caminho, esta sociedade que, no início, ainda se vinculava as ditas sociedades de produção, foi se afastando destas, para se consolidar em uma sociedade de consumo. Isto se solidificou porque houve um aumento da produção, impulsionado pela industrialização, tendo como base o desenvolvimento tecnológico. Assim, o consumo vem embalado no berço

\footnotetext{
${ }^{3}$ Nesse sentido pode-se verificar: "El Consumocentrismo: filosofía empresarial centrada en el consumidor." "El programa Rumbo Económico de Canal N (Lima-Perú) nos hizo una entrevista para conocer las implicancias de poner al consumidor al centro de las decisiones de negocio, una filosofía que se conoce como "consumocentrismo" en el ámbito empresarial. Aquí el extracto de la entrevista: CONSUMER-INSIGHTS. Disponível em: http://consumer-insights.blogspot.com/. Acesso em: 30 agosto 2019.
} 
da modernidade e da revolução industrial. Porém, é no pós Segunda Grande Guerra, ou seja, na segunda do século $\mathrm{XX}$, que desponta o desenvolvimento do que seria denominado de consumo exagerado, - anos 50, 60, 70, dependendo do Estado - dando encaminhamento para o desenrolar do hiperconsumo já no final do século XX, início do século XXI (80, 90, 2000).

Dentro desses períodos - no contexto do consumo - evoluíram as nomenclaturas que impingiam rótulos à propalada sociedade moderna: sociedade de consumo; sociedade hiperconsumista. Estas visões não são suficientes para configurar a sociedade moderna contemporânea, vez que: a ideia de "sociedade de consumo" induz, apenas a uma sociedade que consome, dentro da desconfiguração da sociedade de produtores, para a sociedade de consumidores, em uma modificação mercadológica de mudança de foco. Bauman (2008, p. 13) explica que no final da década de 1920 a transformação da sociedade de produtores em sociedade de consumidores estava iminente e passava despercebida de observadores menos atentos.

Por outro lado, falar de sociedade de hiperconsumo pressupõe um trabalho sobre a sociedade moderna através do superlativo "hiper", o que, também, não parece que ser o suficiente, vez que o superlativo "hiper", na forma que foi e é trabalhado, induz a uma perspectiva de que o consumo já atingiu o seu auge, o que, sem sobra de dúvidas, não favorece ao contexto social configurado na atualidade. O hiperconsumo, não é o cerne, o centro da sociedade moderna contemporânea, ele é apenas consequência do consumocentrismo, este sim é o elemento fundamental do desenvolvimento desta sociedade, por isto o centro, o elemento primeiro na discussão, que envolve todo o sistema, inclusive o capitalismo.

Na realidade, o capitalismo e o consumo estão configurados na modernidade, porém o que se deve abordar, para o presente artigo, não são as características de um ou de outro, mas sim o como esses elementos estão sendo trabalhados e o como isto integraliza, hoje, o ser humano enquanto "ser" que adota esta nova religião, trocando Deus, que já sofreu os embates do antropocentrismo, pelo consumo. Assim não é o "hiper" que preocupa, mas sim a inconsciência do consumo, que na abstração do ser, se concretiza na alienação dele na esfera psicossocial.

Alienação esta, que se desnuda no consumocentrismo vinculando-se as visões individualistas onde o mercado é pelo mercado, a tecnologia pela tecnologia e o indivíduo 
pelo indivíduo. Trazendo a questão para a autonomia do indivíduo nessa sociedade, bem coloca Retondar:

\begin{abstract}
No interior desse contexto, a questão da autonomia do indivíduo e seu desdobramento enquanto "Sujeito" dos processos sociais, um dos princípios do racionalismo moderno, irá constituir um dos principais focos da discussão em torno do desenvolvimento da sociedade de consumo. Isto porque, atrelada a esta ideia, se encontra as noções de massificação e homogeneização, sociedade de massas e cultura de massas, as quais pressupõem, como condição axiológica, a sobreposição de estruturas e processos sociais sobre a autonomia do indivíduo enquanto "Sujeito" dos processos sociais. (RETONDAR, 2007, pp. 69-70)
\end{abstract}

A massificação dentro da sociedade consumocentrista é um dos elementos que proporciona o endereçamento do cidadão ao consumo, porque, dessubjetivado de sua cidadania e impregnado com a cultura de massas, esse indivíduo se torna, apenas, um consumidor homogeneizado, que não se preocupa em nada mais que o consumir.

Nesta ótica, ainda há que se dizer que consumo sempre existiu, o desejo pela ou pelas coisas sempre existiu. Este elemento é fundamental para se entender a nova sociedade que foi inaugurada, basicamente, na contemporaneidade, ou seja, nos últimos 50 anos. Esta nova sociedade tem como elemento fundamental o consumo incrustado no ser humano, que antes era chamado de cidadão e hoje é chamado de consumidor. Assim, diferentemente do que acontecia nas sociedades pré-consumocentrista, hoje o indivíduo adota como conduta central e como pensamento central de sua vida o consumo, o que, na realidade, antes, na sociedade pré-consumocentrista, não ocorria. O desejo do consumo se diferenciava da existência do ser. A partir da interpretação de René Descartes (1973) que se tem Je pense, donc je suis, ("penso, então eu estou", ou na interpretação mais usada: "penso logo existo"); o consumocentrismo inaugura o outro lado: J'achète bientôt existe (Eu compro, logo existo).

Assim, o que se denominou de consumismo ou hiperconsumo - MODERNIDADE HIPERCONSUMISTA - se fundamenta em um consumo que proporciona ao cidadão uma elevação em seu status social, porém, aqui se está dentro de uma racionalidade consumista/hiperconsumista - consciência do consumo como objeto do desejo. Por outro lado, na sociedade consumocentrista esta consciência já não existe mais. O sujeito é dessubjetivado, deixando de ser sujeito, ator de seus desejos, para ser simplesmente consumidor, sem as interfaces sociais que o levam a ser participe/responsável pela história e pela sociedade; deixa de ser cidadão para ser consumidor de tudo e de nada ao mesmo tempo. 
Esse novo ser, consumidor, gerado pela sociedade consumocentrista detém seu foco no consumo, este como elemento perfectibilizador do próprio ser. Antes consumidor, longe de tudo e de todos. Inconsciente dos reflexos de seus atos, alienado de qualquer consequência, não senciente e não consciente dos problemas sociais.

É nessa sociedade consumocentrista, configurada sobre estruturas endeusadoras do consumo, que a modernidade demostra seu lado sombrio, socialmente, sobre os excluídos quase metade da população mundial — 3,4 bilhões de pessoas - ainda luta para satisfazer as necessidades básicas (NAÇÕES UNIDAS, 2019) ${ }^{4}$; ambientalmente, sobre a natureza destruição dos ecossistemas, desparecimento de espécimes, destruição de florestas, poluição do solo, água e ar... -

Como se pode notar, a preocupação dos Autores, até o presente momento, foi deixar configurado o estado social em que se desenvolve o artigo, a sociedade consumocentrista, vez que o uso dos bens da natureza está diretamente ligado ao mercado e ao lucro das grandes corporações, conforme se verá no próximo item.

\section{O DIREITO AO MEIO AMBIENTE ECOLOGICAMENTE EQUILIBRADO: OS DANOS SOCIOAMBIENTAIS PRODUZIDOS PELA SOCIEDADE CONSUMOCENTRISTA EM DESFAVOR DA SUSTENTABILIDADE}

O ponto de partida do presente item é a Constituição Federal do Brasil de 05 de outubro de 1988, precisamente no Título VIII - da ordem social -, capítulo VI - do meio ambiente -, artigo 225, caput, que assim dispõe: “Todos têm direito ao meio ambiente ecologicamente equilibrado, bem de uso comum do povo e essencial à sadia qualidade de vida, impondo-se ao Poder Público e à coletividade o dever de defendê-lo e preservá-lo para as presentes e futuras gerações." (BRASIL, CF/88, 2019).

O legislador constitucional se manifestou claramente no presente dispositivo legal, estabelecendo o meio ambiente ecologicamente equilibrado como um direito de todos os cidadãos e não só para as gerações atuais, mas também para as gerações futuras, o que

\footnotetext{
${ }^{4}$ Dados das NAÇÕES UNIDAS. Banco Mundial. Disponível em: https://nacoesunidas.org/banco-mundialquase-metade-da-populacao-global-vive-abaixo-da-linha-da-pobreza/. Acesso em: 30 agosto 2019.
}

Revista de Direito e Sustentabilidade | e-ISSN: 2525-9687 | Belém | v. 5 | n. 2 | p. 01 - 19 | Jul/Dez. 2019. 
solidifica a ideia de sustentabilidade, embora a palavra não apareça expressamente no texto constitucional.

Conforme se vem dispondo no presente artigo, a modernidade solidificou o sujeito em uma sociedade consumocentrista, sendo que o Brasil não fugiu a esta regra. $O$ Consumocentrismo moderno é o responsável pelos danos causados à sociedade e ao meio em todos os âmbitos, pois para sustentar o modelo de consumo, acumulação e descarte imposto, optou-se: em primeiro lugar, pela exacerbada extração dos recursos naturais, como atuação necessária à produção dos bens de consumo; em segundo, pela acumulação desses bens e/ou acumulação dos resultados econômicos gerados por eles; em terceiro, pela geração de poluição das águas, da terra e do ar e, por consequência, causando riscos à saúde humana. Como se podem ver todos os aspectos dispostos neste parágrafo em nada atende ao dispositivo constitucional acima elencado.

Embora o consumocentrismo alienante, algumas entidades não governamentais e, também, alguns governos começaram a se preocupar com os problemas socioambientais gerados pelo contexto moderno consumocentrista, principalmente após alguns eventos catastróficos que aconteceram em várias partes do mundo, assim:

\begin{abstract}
Pode-se dizer que, até o início da década de 1970, o pensamento mundial dominante era o de que o meio ambiente seria fonte inesgotável de recursos e que qualquer ação e aproveitamento da natureza fossem infinitos. Mas fenômenos como secas que afetaram lagos e rios, a chuva ácida e a inversão térmica fizeram com que essa visão ambiental do mundo começasse a ser questionada, com base em estudos científicos que identificavam problemas especialmente por conta da poluição atmosférica.

Assim, foi convocada a Conferência das Nações Unidas para o Meio Ambiente Humano, realizada em Estocolmo, Suécia, em junho de 1972, que produziu a Declaração sobre Ambiente Humano, ou Declaração de Estocolmo, e estabeleceu princípios para questões ambientais internacionais, incluindo direitos humanos, gestão de recursos naturais, prevenção da poluição e relação entre ambiente e desenvolvimento, estendendo-se até a necessidade de se abolir as armas de destruição em massa. A conferência também levou à elaboração do Programa das Nações Unidas para o Meio Ambiente, que deu continuidade a esses esforços.(BRASIL, SF, 2019). ${ }^{5}$
\end{abstract}

\footnotetext{
${ }^{5}$ Em BRASIL. Senado Federal. Da Conferência das Nações Unidas para o Meio Ambiente Humano, em Estocolmo, à Rio-92: agenda ambiental para os países e elaboração de documentos por Comissão Mundial sobre Meio Ambiente e Desenvolvimento. https://www.Senado.Gov.Br/Noticias/Jornal/Emdiscussao/Rio20/ARio20/Conferencia-Das-Nacoes-Unidas-Para-O-Meio-Ambiente-Humano-Estocolmo-Rio-92-AgendaAmbiental-Paises-Elaboracao-Documentos-Comissao-Mundial-Sobre-Meio-Ambiente-E-Desenvolvimento.Aspx - Acesso em 30 agosto 2019.
} 
Optou-se por não referir os eventos de catástrofes recentes de rompimento de barragens no Brasil, tendo em vista que estes não estariam elencados entre aqueles os que auxiliaram na formação da preocupação com os problemas socioambientais gerados pela sociedade moderna consumocentrista.

Além dos eventos, acima elencados, ainda se tem levado em conta o aquecimento global (Efeito estufa); o buraco na camada de ozônio e o desgelo das calotas polares.

Estes são apenas alguns dos exemplos que demonstram a necessidade de se buscar alternativas ao modelo ambientalmente incorreto e socialmente excludente criado com a modernidade e consolidado na sociedade consumocentrista, como se pode verificar nos próximos parágrafos.

A modernidade é a gênese do desenvolvimento econômico e, também, a motivadora do consumocentrismo que, como se vem discorrendo, trouxe consequências nefastas ao contexto socioambiental.

No plano social, a proposta inicial da modernidade foi ser o elemento capaz de satisfazer as necessidades humanas, trazendo felicidade a todos através da ciência e da tecnologia. Porém a modernidade não se perfectibilizou a todos e, como consequência disto, os paradoxos foram inevitáveis tanto no âmbito do discurso, quanto na prática científica.

No discurso podem-se notar incoerências patentes, senão vejamos: "todos os brasileiros podem ter um e-mail", ou, "consumindo você será feliz". Um discurso incoerente com a realidade, onde grande camada da população brasileira não possui acesso à internet, luz elétrica e saneamento básico; ou, no segundo discurso, onde grande parte da população não possui acesso ao consumo, vivendo abaixo da linha da miséria.

$\mathrm{Na}$ ciência e na tecnologia, somente uma pequena parcela das pessoas possuem suas benesses, seja na área dos medicamentos, eletrodomésticos, automóveis, aviões, etc., ou seja, existem pessoas capazes de colocar um foguete em marte e, por outro lado, pessoas vivendo no neolítico.

O acesso à alimentação - nutrição adequada - também se demonstra desigual. Se por um lado aumentam as pessoas com obesidade, por outro aumentam as pessoas com fome.

A revolução industrial, forjada na ciência e na tecnologia, apareceu como elemento que possibilitaria a implantação dos ideais da modernidade, muito bem representados na tríade exposta pela revolução francesa - liberdade, igualdade e fraternidade. Os séculos 
avançaram e a revolução industrial demonstrou-se também contraditória. As contradições da revolução industrial revelaram-se na concentração de renda versus a escravidão branca; na exploração da mão de obra pelo capital e na destruição do meio ambiente.

Uma análise superficial sobre os problemas socioambientais produzidos pela sociedade consumocentrista e elencados neste item, poderia induzir o interprete ao erro de entender, que, tendo em vista se demonstrado que muitas pessoas não possuem acesso às benesses da modernidade - principalmente o consumo - os problemas ambientas não poderiam estar atrelados aos parâmetros modernos. Porém esta conclusão não é verdadeira, porque é justamente no consumo exacerbado da população que possui acesso às benesses modernas que está a maioria dos problemas ambientais. Por outro lado, a população menos desfavorecida, embora excluída dos processos consumeristas mais importantes, são partícipes, de uma forma, ou outra, da sociedade consumocentrista, nem que seja de suas migalhas. Sobre as questões ambientais é de se trazer o pensamento de Beck:

O impacto ambiental da indústria e a destruição da natureza, que, com seus diversos efeitos sobre a saúde e a convivência das pessoas, surgem originalmente nas sociedades altamente desenvolvidas, são marcados por um déficit do pensamento social. Soma-se a esse déficit o grotesco: ninguém se dá conta dessa ausência sequer os próprios sociólogos. (BECK, 2010, p. 30)

Como se demonstrou até este ponto do artigo, é urgente uma modificação nos parâmetros que norteiam a sociedade moderna consumocentrista em termos globais e, em particular no Estado brasileiro. Verificou-se que, no âmbito global, o meio ambiente dá mostras claras de não mais estar suportando o nível de poluição impingido pelos atos humanos - aquecimento global, desgelo das calotas polares, buraco na camada de ozônio, chuvas ácidas em diversas partes do planeta -; em termos particulares, Brasil, não foge a regra pois se inclui dentro do sistema global, porém é de se lembrar a atuação humana - poluição nos desastres ambientais dos rompimentos das barragens da empresa Vale; desmatamento crescente da Amazônia; uso indiscriminado de agrotóxicos - que está em desacordo com os mandamentos constitucionais trazidos para este artigo.

A manutenção do sistema atual, que possui o consumo como elemento fundamental da vida, endereça os atos humanos à destruição do meio ambiente, vez que, também baseados no antropocentrismo, que considera a natureza como bem a ser explorado e destruído para satisfação humana. Nesta seara, em que a natureza é apenas bem comum para uso, longe da 
possibilidade de ser ela detentora do "Status de Sujeito de Direito", as ações desmedidas sobre ela são continuamente exercidas, impossibilitando a real sustentabilidade tão almejada.

Neste último particular, buscando uma cultura socioecológica expressa pelos direitos da natureza é que se desenvolverá o próximo título deste artigo, na esperança de se vislumbrar soluções adequadas ao caos socioambiental gerado pelo modelo social da modernidade consumocentrista.

\section{A CULTURA SOCIOECOLÓGICA EXPRESSA PELOS DIREITOS DA NATUREZA EM FACE À SOCIEDADE MODERNA CONSUMOCENTRISTA}

Conforme se vem verificando, a sociedade consumocentrista moderna tem por característica a geração de problemas socioambientais, tais como: a degradação ambiental, a poluição, mas também, a desigualdade social e a pobreza. São problemas prementes que precisam de uma nova cultura no que se refere aos direitos da natureza.

A natureza precisa ser preservada por seu valor intrínseco e não porque ela é somente importante para as gerações atuais e futuras. A vida humana depende da proteção da casa comum, a qual perpetuará todas as espécies humanas e não-humanas. Com isso, os países latino americanos - Bolívia, Equador, Venezuela, etc., vislumbram um preceito constitucional diferenciado estabelecendo constituições inovadoras no que se refere a proteção dos direitos da natureza. Utiliza-se como marco da presente pesquisa o Equador, sendo estudada a Constituição Equatoriana de 2008 a fim de demonstrar a preocupação com os direitos da natureza.

Existe uma preocupação dos Autores do trabalho no que se refere aos impactos da sociedade consumocentrista moderna principalmente na questão de docilização e adestramento das pessoas pelo consumo exagerado. Para Rocha,

\footnotetext{
o consumo é uma realidade simbólica de significados tão densos que merece uma reflexão livre do viés aplicado que impera no mundo dos negócios. O estudo sistemático do consumo permitiria desvendar um dos mais importantes códigos através do qual a cultura contemporânea elabora a experiência da diferença, constrói um sistema de classificações sociais e interpreta as relações entre as coisas e as pessoas. (2002, p.05).
}

Com isso se observa nesse sentido segundo Pereira e Calgaro que: 
Essa cultura consumista se desenvolve, também, a partir de uma educação que cria o desejo pelo consumo, pelo descarte, pela valorização do novo. O velho se torna ultrapassado e sem sentido. Porém, as consequências dessas atitudes não tem qualquer proeminência para o "ser consumidor". Consumir se torna a palavra mágica, capaz de transformar a vida do indivíduo, alçando-o ao patamar de detentor de status e de poder no mundo, fazendo com que este se sinta grandioso, o "deus" de possibilidades e de oportunidades. (PEREIRA; CALGARO, 2014, p. 14).

Continuando na percepção de Pereira e Calgaro "essa felicidade é incognoscível, pois, no fundamento do mercado moderno, ela deve ser sempre procurada e nunca é saciada. $\mathrm{Na}$ atualidade a fórmula do consumo é: buscar uma felicidade que, ao ser tocada, evanesce e esmorece para que ela seja buscada novamente e continuamente todos os dias". (PEREIRA; CALGARO, 2014, p. 13). Assim, “o consumismo é global, não no sentido de que todos podem consumir, mas no de que todos são afetados por ele" (LYON, 1998, p.104). Assim sendo, a "lista de malefícios gerados por uma sociedade de consumo, que vem se caracterizando como hiperconsumista e que consome mais pelo desejo de consumir do que pela necessidade é interminável" (PEREIRA; PEREIRA, 2010, p. 94).

Dessa forma é preciso encontrar uma viabilidade a problemática apresentada entendendo-se que é preciso encontrar um caminho que leve a sustentabilidade. De acordo com Leff a sustentabilidade "aponta para um futuro, para uma solidariedade transgeracional e um compromisso com as gerações futuras. O futuro é uma exigência de sobrevivência e um instinto de conservação.” (LEFF, 2001, p. 412). O desenvolvimento sustentável exige planejamento no que tange ao crescimento do "desenvolvimento - progresso -, mas os cidadãos devem participar e tomar conhecimento de sua condição nesse planeta e em seus projetos, tanto sociais como políticos, que devem apontar para um ordenamento ecológico e a retomada de valores inerentes à espécie humana" (PEREIRA; CALGARO, 2016, p. 35).

Com base no exposto observa-se a necessidade de uma cultura socioecológica no intuito de se atingir a sustentabilidade e de proteger os direitos da natureza. Para tal, o constitucionalismo latino americano equatoriano ${ }^{6}$ acaba sendo inovador ao designar a

\footnotetext{
${ }^{6}$ Wolkmer (2014, p. 1006), a Constituição Equatoriana protagoniza "um giro biocêntrico, fundado nas cosmovisões dos povos indígenas". E, continua "possivelmente, o momento primeiro e de grande impacto para o "novo" constitucionalismo latino-americano vem a ser representado pela Constituição do Equador de 2008, por seu arrojado "giro biocêntrico", admitindo direitos próprios da natureza e direitos ao desenvolvimento do "bem viver". A inovação desses direitos não impede de se reconhecer os avanços gerais e o enriquecimento dos direitos coletivos como "direitos das comunidades, povos e nacionalidades", destacando a ampliação de seus sujeitos, dentre as nacionalidades indígenas, os afro-equatorianos, comunais e os povos costeiros (arts. 56 e 57)". (WOLKMER, 2013, p.33).
} 
natureza como sujeito de direitos e assim implementar uma ordem constitucional moderna e inovadora. Desta forma, o art. 10 traz a percepção da natureza como sujeito de direitos, no qual: "Las personas, comunidades, pueblos, nacionalidades y colectivos son titulares y gozarán de los derechos garantizado sem la Constitución y enlos instrumentos internacionales.

La naturaleza será sujeto de aquellos derechos que le reconozca la Constitución". (ECUADOR, 2008). Importante direcionar também para art. 71 o qual permite verificar uma preocupação com a mãe terra: "La naturaleza o Pacha Mama, donde se reproduce y realiza la vida, tiene derecho a que se respete integralmente su existencia y el mantenimiento y regeneración de sus ciclos vitales, estructura, funciones y procesos evolutivos" (ECUADOR, 2008). A partir do exposto a natureza acaba tendo os ciclos vitais preservados em com isso, acaba sendo protegida pelo seu valor intrínseco. Esse preceito constitucional admite uma visão pluralista, holista e participativa, onde o povo é integrante ativo da sociedade e tem o dever de proteger a natureza e seus direitos.

A participação e a nova percepção do ser humano são fundamentais na sociedade moderna consumocentrista como forma, até mesmo, de contraposição à visão capitalista do mercado e de progresso econômico, no qual o "aparentar" "ter" e "ser" é superior ao "ser", o que denota que não se consegue romper os grilhões do antropocentrismo ${ }^{7}$ para se chegar a uma cooperação social, pois no momento se tem lugar a um individualismo, o qual faz com que os bens materiais sejam valorizados e assim o ser humano é precificado. Se o ser humano é precificado a natureza acaba sendo o instrumento pelo qual se extrai e degrada a fim de atingir os desejos do consumo exagerado e fútil.

É preciso um equilíbrio entre a sociedade, o ser humano e o meio ambiente a fim de que se vislumbre um futuro comum. A cultura socioecológica pode ser o caminho, visto que os direitos da natureza sendo protegidos traz essa nova percepção mais holística de mundo, o qual permite que se possa crescer, mas de forma a respeitar os ciclos vitais do planeta. É preciso lembrar que a natureza possui recursos que são finitos e o extrativismo dos países em desenvolvimento, como por exemplo, o Brasil e o próprio Equador somente levam a devastação ambiental e social. Sabe-se que apesar do preceito constitucional equatoriano de proteção aos direitos da natureza estar vigente, o mesmo não é tão eficaz, visto que o poder

\footnotetext{
${ }^{7}$ Maddalena (1990, p. 84) "ad um principio antropocentrico si va lentamente sostituendo un principio biocentrico; ovviamente, non nel senso che al valore uomo si sostittuisce il valore natura, ma nel senso che si pone como valore la "comunità biotica', al cui vertice sta l'uomo".
}

Revista de Direito e Sustentabilidade | e-ISSN: 2525-9687 | Belém | v. 5 | n. 2 | p. 01 - 19 | Jul/Dez. 2019. 
econômico de países desenvolvidos, de grandes corporações e mercados impera de forma devastadora devido ao consumo que se tornou um instrumento de fortificação econômica, de adestramento e dessubjetificação social e de degradador ambiental.

Uma cultura socioecológica permite que o ser humano se veja como parte da natureza e não como ser superior que pode impor suas regras sem que haja uma contrapartida. Isso porque segundo Molinaro "nós não estamos no entorno, "nós somos o entorno"” (2006, p. 52).

\section{CONSIDERAÇÕES FINAIS}

A sociedade consumocentrista acaba por induzir a utilização de recursos naturais de forma exagerada, com isso se esquece que esses recursos são finitos e que a natureza precisa ser preservada em seu valor intrínseco, tendo seus ciclos vitais garantidos. A partir disso o objetivo principal foi respondido no sentido de que existem critérios a serem observados para a proteção dos direitos da natureza que a sociedade consumocentrista mascara e deteriora na modernidade.

Também os dois problemas secundários diagnosticados e que perfazem a base central do artigo, podem ser vislumbrados no sentido de que é preciso uma nova cultura ecológica no intuito de proteger a casa comum e, com isso, respeitar a integralidade da natureza. Além disso, é preciso minimizar os problemas socioambientais advindos do consumocentrismo e para isso, o Equador apresenta uma alternativa, transformando a natureza como sujeito de direitos em seu preceito constitucional. A sustentabilidade é outra alternativa a ser trilhada a partir de uma cultura socioecológica, na qual o ser humano perceba que é parte do todo e não o centro do todo.

A sociedade consumocentrista adestra e dociliza o cidadão, transformando-o em consumidor. Nesse contexto, as grandes corporações e o mercado fragilizam as relações interpessoais e o "deus" consumo impera, devastando tanto os seres humanos como o meio ambiente, por isso a percepção de que é preciso que se resolvam os problemas socioambientais. Parcelas de pessoas não podem estar envoltas pela pobreza, sendo marginalizadas pela desigualdade social. Por outro lado, o meio ambiente não pode sofrer com o extrativismo exacerbado que o degrada, não permitindo que os ecossistemas possam se recuperar.

Revista de Direito e Sustentabilidade | e-ISSN: 2525-9687 | Belém | v. 5 | n. 2 | p. 01 - 19 | Jul/Dez. 2019. 
Desta forma uma cultura socioecológica permite que se proteja não somente o ser humano, mas a natureza por seu valor intrínseco e não porque a mesma é essencial para as futuras gerações.

\section{REFERÊNCIAS}

BAUMAN, Zygmunt. Vida para o consumo. Rio de Janeiro: ZAHAR, 2008.

BRASIL. Senado Federal. Da Conferência das Nações Unidas para o Meio Ambiente Humano, em Estocolmo, à Rio-92: agenda ambiental para os países e elaboração de documentos por Comissão Mundial sobre Meio Ambiente e Desenvolvimento. Disponível em: <https://www.Senado.Gov.Br/Noticias/Jornal/Emdiscussao/Rio20/A-Rio20/ConferenciaDas-Nacoes-Unidas-Para-O-Meio-Ambiente-Humano-Estocolmo-Rio-92-Agenda-AmbientalPaises-Elaboracao-Documentos-Comissao-Mundial-Sobre-Meio-Ambiente-EDesenvolvimento.Aspx> - Acesso em 30 agosto 2019.

BRASIL. Constituição Federal de 1988. Disponível em: < http://www.planalto.gov.br/ccivil_03/constituicao/constituicaocompilado.htm>. Acesso em 30 agosto 2019.

BECK, Ulrich. Sociedade De risco: rumo a uma outra modernidade. São Paulo: Editora 34, 2010 .

BRÜSEKE, Franz Josef: A modernidade técnica: contingência, irracionalidade e possibilidade. Florianópolis: Editora Insular, 2010.

CALGARO, Cleide; PEREIRA, Agostinho Oli Koppe Pereira. O constitucionalismo latinoamericano e a sociedade consumocentrista: por uma democracia socioecológica. In. Direito socioambiental [recurso eletrônico] organização Cleide Calgaro. - Caxias do Sul, RS: Educs, 2018.

CONSUMER INSIGHTS. Disponível em: http://consumer-insights.blogspot.com/. Acesso em: 30 agosto 2019.

DESCARTES, René. Discurso do método. São Paulo: Abril Cultural, 1973. 336 p. (Os pensadores 15).

EQUADOR. Constituição (2008). Constitución del Ecuador. Disponível em: $<$ http://www.presidencia.gob.ec/index.php?option=com_remository\&Itemid=90\&func=fileinf o\&id=2>. Acesso em: 30 agosto 2019.

GIDDENS, Anthony. As consequências da modernidade. São Paulo: Editora UNESP, 1991.

Revista de Direito e Sustentabilidade | e-ISSN: 2525-9687 | Belém | v. 5 | n. 2 | p. 01 - 19 | Jul/Dez. 2019. 
LEFF, Enrique. Saber ambiental: sustentabilidade, racionalidade, complexidade, poder. Tradução: Lúcia Mathilde Endlich Orth. Petrópolis, RJ: Vozes, 2001

LYON. David. Pós-modernidade. São Paulo: Paulus, 2005.

LYON, David. Pós-modernidade. São Paulo: Paulus, 1998.

MADDALENA, Paolo. Danno pubblico ambientale. Rimini: Maggioli Editores, 1990.

MOLINARO, Carlos Alberto. Racionalidade ecológica e estado socioambiental e democrático de direito. Dissertação (Mestrado em direito) - Faculdade de Direito, Pontifícia Universidade Católica do Rio Grande do Sul Porto Alegre, 2006. Disponível em: Acesso em: 30 agosto 2019.

NAÇÕES UNIDAS. Banco Mundial. Disponível em: https://nacoesunidas.org/bancomundial-quase-metade-da-populacao-global-vive-abaixo-da-linha-da-pobreza/. Acesso em: 30 agosto 2019.

PEREIRA, Agostinho Oli Koppe; CALGARO, Cleide. A modernidade e o hiperconsumismo: políticas públicas para um consumo ambientalmente sustentável. In: PEREIRA, Agostinho Oli Koppe; HORN, Luiz Fernando Del Rio (Orgs.). Relações de consumo: políticas públicas. Caxias do Sul, RS: Plenum, 2015.

PEREIRA, Agostinho Oli Koppe; CALGARO, Cleide. Desenvolvimento sustentável e o consumocentrismo: o paradoxo da modernidade. In: PEREIRA, Agostinho Oli Koppe; CALGARO, Cleide; PEREIRA, Henrique Mioranza Koppe. O consumo na sociedade moderna consequências jurídicas e ambientais. Caxias do Sul: EDUCS, 2016, p. 35.

PEREIRA; Agostinho Oli Koppe; PEREIRA, Henrique Mioranza Koppe. Relação de consumo e modernidade: consequências desta interação sobre os riscos ao meio ambiente. In: PILAU SOBRINHO, Liton Lanes; SILVA, Rogerio da. (Org.). Balcão do Consumidor: relações de consumo. Passo Fundo: UPF Editora, 2010.

PEREIRA, Agostinho Oli Koppe; CALGARO, Cleide. Os riscos ambientais advindos dos resíduos sólidos e o hiperconsumo: a minimização dos impactos ambientais através das políticas públicas. In: PEREIRA, Agostinho Oli Koppe; CALGARO, Cleide; HORN, Luiz Fernando Del Rio (Orgs.). Resíduos sólidos: consumo, sustentabilidade e riscos ambientais. Caxias do Sul, RS: Plenum, 2014.

PEREIRA, Agostinho Oli Koppe; LUNDGREN, Ana Paula; TONIASSO, Rachel Cassini. O hiperconsumo e os riscos ambientais provocados por resíduos sólidos: uma análise da política nacional dos resíduos sólidos, tendo Caxias do Sul como referência. In: PEREIRA, Agostinho Oli Koppe; CALGARO, Cleide; HORN, Luiz Fernando Del Rio (Orgs.). Hiperconsumo, riscos ambientais: provocados pelos resíduos sólidos e políticas públicas nos municípios de Caxias do Sul e Passo Fundo. Caxias do Sul, RS: Plenum, 2014.

PEREIRA, Agostinho Oli Koppe; CALGARO, Cleide; PEREIRA, Henrique Mioranza Koppe. Consumocentrismo e os seus reflexos socioambientais na sociedade contemporânea. Revista Direito Ambiental e Sociedade, v. 6, p. 264-279, 2016.

Revista de Direito e Sustentabilidade | e-ISSN: 2525-9687 | Belém | v. 5 | n. 2 | p. 01 - 19 | Jul/Dez. 2019. 
PEREIRA, Agostinho Oli Koppe; SIMIONI, Rafael Lazzarotto. Da maximização à eficiência: o sentido de consumo na semântica econômica moderna. PEREIRA, Agostinho Oli Koppe; HORN, Luiz Fernando del Rio (Org.). Relações de Consumo: Consumismo. Caxias do Sul: Educs, 2010.

ROCHA, Everardo P. Guimarães. Cenas do Consumo: Notas, Idéias, Reflexões. Revista Semear, n. 06, Rio de Janeiro: PUC - Rio, 2002.

RETONDAR, Anderson Moebus. Sociedade de consumo, modernidade e globalização. São Paulo: Annablume; Campina Grande: EDFCG, 2007.

WOLKMER, Antonio Carlos. Pluralismo e Crítica do Constitucionalismo na América Latina. 2014. In.: Anais do IX Simpósio Nacional de Direito Constitucional. Disponível em <http://www.abdconst.com.br/revista3/antoniowolkmer.pdf>. Acesso em 20 agosto 2019.

WOLKMER, Antonio Carlos. Pluralismo crítico e perspectivas para um novo constitucionalismo na América Latina. In: WOLKMER, Antonio Carlos; MELO, Milena Petters. Constitucionalismo latino - americano:tendências contemporâneas. Curitiba: Juruá, 2013.

WOLKMER, Antonio Carlos. Pluralismo Jurídico: fundamentos de uma nova cultura no Direito. 3 ed. São Paulo: Alfa-Omega, 2001, 